\title{
A Plasmonic Mass Spectrometry Approach for Detection of Small Nutrients and Toxins
}

\author{
Shu $\mathrm{Wu}^{1} \cdot$ Linxi Qian ${ }^{2} \cdot$ Lin Huang ${ }^{1} \cdot$ Xuming Sun ${ }^{1} \cdot$ Haiyang $\mathrm{Su}^{1} \cdot$ Deepanjali D. Gurav ${ }^{1} \cdot$ Mawei Jiang $^{2} \cdot$ \\ Wei $\mathrm{Cai}^{2} \cdot$ Kun Qian ${ }^{1}$
}

Received: 3 March 2018/Accepted: 17 April 2018/Published online: 17 May 2018

(C) The Author(s) 2018

\section{Highlights}

- New materials-based methods. Sensitive detection of small nutrients and toxins $(\sim$ pmol $)$ was performed based on plasmonic nanoparticles.

- Advanced analytical performance. Fast quantitation and identification of target molecules (in minutes) were directly achieved in complex emulsion samples.

\begin{abstract}
Nutriology relies on advanced analytical tools to study the molecular compositions of food and provide key information on sample quality/safety. Small nutrients detection is challenging due to the high diversity and broad dynamic range of molecules in food samples, and a further issue is to track low abundance toxins. Herein, we developed a novel plasmonic matrix-assisted laser desorption/ionization mass spectrometry (MALDI MS) approach to detect small nutrients and toxins in complex biological emulsion samples. Silver nanoshells $\left(\mathrm{SiO}_{2} @\right.$ $\mathrm{Ag}$ ) with optimized structures were used as matrices and
\end{abstract}

Shu Wu and Linxi Qian have contributed equally to this work.

Electronic supplementary material The online version of this article (https://doi.org/10.1007/s40820-018-0204-6) contains supplementary material, which is available to authorized users.

\section{Wei Cai \\ caiw1978@163.com \\ k.qian@sjtu.edu.cn}

$\triangle$ Kun Qian

1 School of Biomedical Engineering, Med-X Research Institute, Shanghai Jiao Tong University, Shanghai 200030, People's Republic of China

2 Xinhua Hospital, Shanghai Institute for Pediatric Research, Shanghai Jiao Tong University, Shanghai 200092, People's Republic of China

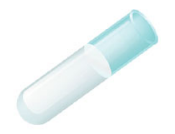

Breast milk

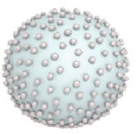

$\mathrm{SiO}_{2} @ \mathrm{Ag}$
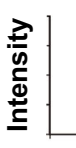
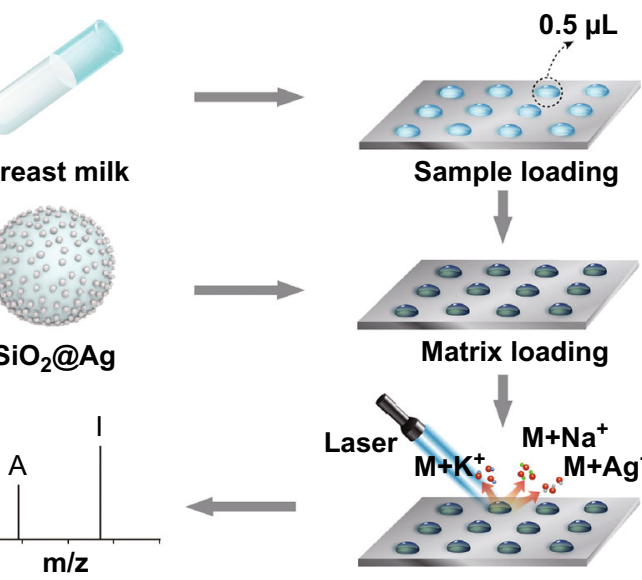

Sample loading
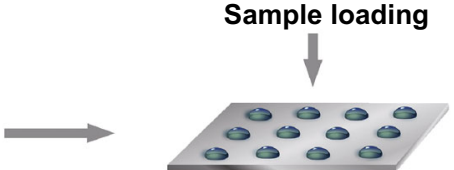

Matrix loading

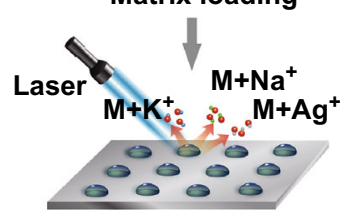

achieved direct analysis of $\sim 6 \mathrm{~nL}$ of human breast milk without any enrichment or separation. We performed identification and quantitation of small nutrients and toxins with limit-of-detection down to $0.4 \mathrm{pmol}$ (for melamine) and reaction time shortened to minutes, which is superior to the conventional biochemical method currently in use. The developed approach contributes to the near-future application of MALDI MS in a broad field and personalized design of plasmonic materials for real-case bio-analysis. 
Keywords Plasmonic materials - Laser desorption/ ionization · Mass spectrometry $\cdot$ Small nutrients · Toxins

\section{Introduction}

Nutriology in clinics relies on advanced analytical tools to analyze the molecular compositions of food, which may also provide key information on sample quality and safety $[1,2]$. Small nutrient molecules, such as sugar and amino acids, serve as key energy resources and help maintain normal physiological processes in living systems [3-5]. However, detection of small nutrients is challenging, considering the high diversity and broad dynamic range of molecules in food samples. And a further issue is to track small toxins at low concentrations [6-8]. Therefore, a novel tool for analysis of small molecules is in high demand for food industry and clinical nutriology.

Mass spectrometry (MS) affords high accuracy, sensitivity, resolution, and throughput, over conventional approaches, such as nuclear magnetic resonance (NMR), capillary electrophoresis (CE), and biochemical analysis (BCA) [9-13]. Notably, matrix-assisted laser desorption/ ionization (MALDI) MS features simple sample preparation and fast analysis for practical use [14-16]. Still, there are two major obstacles for MALDI MS in analysis of small molecules, including (1) selection of tailored matrix materials for specific application with high efficacy; and (2) quantitation of analytes overcoming the non-predictable desorption/ionization behavior [15, 17]. The aforementioned problems need to be addressed before applying MALDI MS-based techniques in biomedical research and industry use.

Plasmonic materials (usually noble metals) enjoy unique photonic, electronic, and thermal properties, due to the surface plasmons with hot carriers [18, 19]. Plasmonic materials facilitate efficient laser desorption/ionization (LDI) processes for MS with designed structural parameters [20-22], which can be advantageous over conventional carbon [23-25] and silicon materials [26-28] suffering from either laser-induced fragmentation or expensive fabrication costs. Compared to the bulk plasmonic matrices, core-shell plasmonic hybrids display higher yields of hot electrons and nanoscale surface roughness, which result in enhanced LDI performance for biomedical use [19, 29]. To date, numerous efforts have been dedicated to the plasmonic MALDI MS worldwide (including our group) $[15,27,29-31]$. A series of core-shell particles have been developed to detect metabolites in diverse solutions, including cerebrospinal fluids [15], serum [29, 30], culturing buffers [32], and exosome lysate [33] recently. Notably, compared to solution analysis as achieved, the application of core-shell plasmonic hybrids remains to be explored for detection of nutrients and toxins toward food industry and clinical nutriology, in a much more complicated colloid system for emulsion analysis.

Herein, we developed a novel plasmonic MALDI MS approach to detect small nutrients and toxins in complex biological emulsion samples (Fig. 1a). We used silver nanoshells $\left(\mathrm{SiO}_{2} @ \mathrm{Ag}\right)$ with optimized structures as matrices and achieved direct analysis of $\sim 6 \mathrm{~nL}$ of human breast milk without any enrichment or separation. We performed identification and quantitation of small nutrients and toxins with limit-of-detection down to $0.4 \mathrm{pmol}$ (for melamine) and reaction time shortened to minutes, superior to the conventional biochemical method currently in use. Our approach contributes to the near-future application of MALDI MS in a broad field and personalized design of plasmonic materials for real-case bio-analysis.

\section{Experimental}

\subsection{Chemicals and Reagents}

Lactose monohydrate (99.0\%), melamine (99.0\%), ammonium hydroxide (28-30\%), tetraethyl orthosilicate (TEOS, 96\%), ethanol absolute $(99.7 \%)$, silver nitrate $(99.5 \%)$, sodium hydroxide (96\%), sodium borohydride (99\%), potassium hexacyanoferrate $(99.5 \%)$, zinc sulfate (99.5\%), and Whatman No. 1 filter papers were purchased from Sinopharm Chemical Reagent Beijing Co., Ltd (Beijing, China). [UL-13C6glc]-lactose monohydrate (the isotope contained six ${ }^{13} \mathrm{C}$ ) was purchased from Cambridge Isotope Laboratories (CIL, USA). Polyvinylpyrrolidone (PVP, MW $40 \mathrm{kDa}$ ) and bovine serum albumin (BSA) were purchased from Sigma, USA. All aqueous solutions were prepared using deionized water $(18.2 \mathrm{M} \Omega \mathrm{cm}$, Milli$\mathrm{Q}$, Millipore, $\mathrm{GmbH}$ ) throughout all experiments.

\subsection{Materials Synthesis}

$\mathrm{SiO}_{2} @ \mathrm{Ag}$ core-shell particles were synthesized by coating silver nanoparticles on the surface of silica particles. Firstly, mono-dispersed spherical silica particles were prepared as the core using the well-known Stöber method [34]. Then, the as-prepared silica particles $(0.9 \mathrm{~g})$ were dispersed in ethanol absolute $(45 \mathrm{~mL})$ to conduct surface coating by silver mirror reaction. Freshly prepared $[\mathrm{Ag}$ $\left.\left(\mathrm{NH}_{3}\right)_{2}\right]^{+}$ion solution $(0.59 \mathrm{M}, 5 \mathrm{~mL})$ was added to the above particles dispersion and sonicated for $30 \mathrm{~min}$. The dispersed particles were subsequently mixed with $150 \mathrm{~mL}$ of PVP ethanol solution $(0.5 \mathrm{mM})$. The suspension was 
(a)

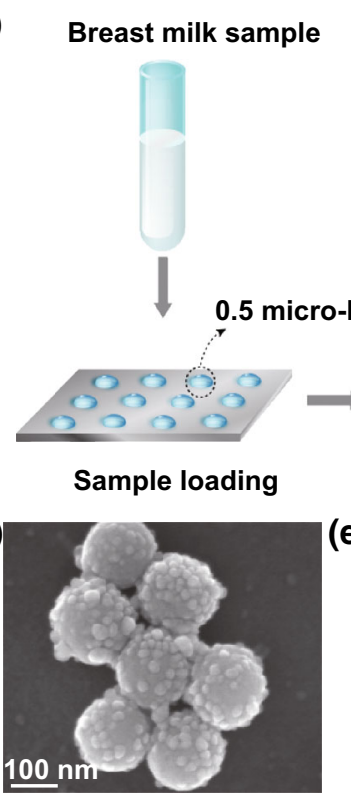

$\mathrm{SiO}_{2} @ \mathrm{Ag}$ nanoshells

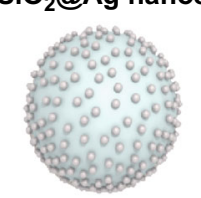

$\downarrow$

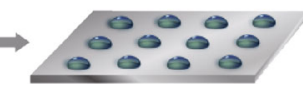

Matrix loading

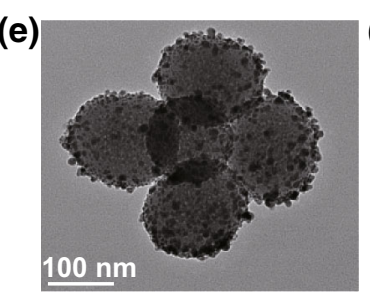

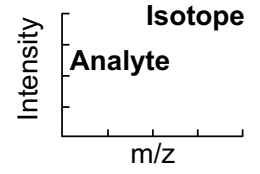

$\mathrm{m} / \mathrm{z}$

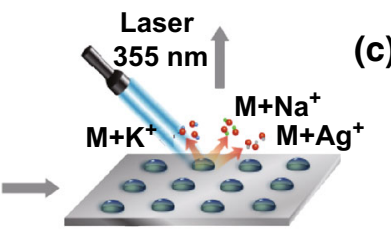

(f)

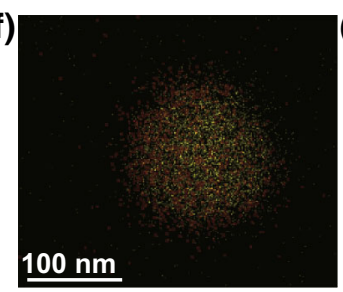

(c) (b)
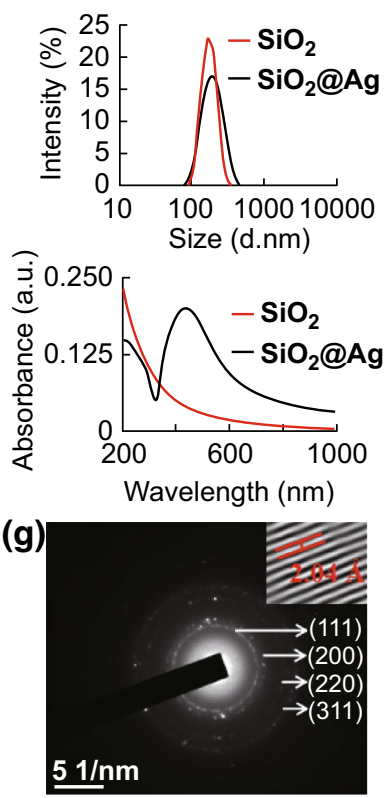

Fig. 1 Overall design and characterizations. a Schematic diagrams of the experimental workflow. b Size distribution of $\mathrm{SiO}_{2}$ and $\mathrm{SiO}_{2} @ \mathrm{Ag}$ particles by DLS. c UV-Vis absorption spectra of $\mathrm{SiO}_{2}$ and $\mathrm{SiO}_{2} @ \mathrm{Ag}$ particles. d SEM, and e TEM images of $\mathrm{SiO}_{2} @ \mathrm{Ag} \mathbf{f}$ Elemental mappings of $\mathrm{SiO}_{2} @ \mathrm{Ag}$ (red for $\mathrm{Ag}$ and yellow for $\mathrm{Si}$ ). g SAED pattern and HRTEM (inset of g) showing the silver crystal lattice

stirred at $70{ }^{\circ} \mathrm{C}$ for $7 \mathrm{~h}$ for the formation of silver layer. The silver mirror reaction was repeated three times to obtain silver nanoshells [15]. Bare silver nanoparticles were prepared as reported [35]. Briefly, $\mathrm{NaBH}_{4}$ solutions ranging in concentration from $\sim 5.0 \times 10^{-4}$ to $2.0 \times 10^{-3} \mathrm{M}$ were chilled in an ice bath under vigorous stirring to form $\mathrm{Ag}$ nanoparticles with different sizes. Then, $\mathrm{AgNO}_{3}\left(10 \mathrm{~mL}, 1.0 \times 10^{-3} \mathrm{M}\right)$ was added and the solution turned light yellow after reaction. The products were washed with ethanol and deionized water three times and dried at $60{ }^{\circ} \mathrm{C}$ and then stored as powders.

\subsection{Materials Characterization}

Transmission electron microscopy (TEM), selected area electron diffraction (SAED) pattern, high-resolution transmission electron microscopy (HRTEM), scanning transmission electron microscopy (STEM), and elemental mapping images were obtained using a JEM-2100F transmission electron microscope (JEOL, Japan). During experiments, ethanol suspension of materials $(\sim 8-10 \mu \mathrm{L})$ was deposited onto a copper grid before observation. Scanning electron microscopy (SEM) images and energydispersive X-ray (EDX) spectra were recorded on an S-4800 field emission scanning electron microscope (Hitachi, Japan) by dropping the material suspensions on aluminum foil. Quantitative elemental analysis was performed on an iCAP6300 inductively coupled plasma optical emission spectrometer (Thermo Fisher Scientific, USA). Room temperature optical absorption spectra of the materials were collected on a UV1900 UV-Vis spectrophotometer (AuCy, China). Zeta potential and dynamic light scattering size measurements were taken on a NanoZS90 instrument in water at $25^{\circ} \mathrm{C}$ (Malvern, Worcestershire, UK).

\subsection{Bio-samples Preparation}

Standard molecules (e.g., lactose and melamine) were dissolved in deionized water by step-wise dilutions with concentrations ranging from $1 \mu \mathrm{g} \mu \mathrm{L}^{-1}$ to $0.1 \mathrm{ng} \mu \mathrm{L}^{-1}$, to study the limit-of-detection (LOD). Standard lactose was mixed with salt $(\mathrm{NaCl}, 0.5 \mathrm{M})$ and the bovine serum albumin (BSA, $5 \mathrm{mg} \mathrm{mL}^{-1}$ ) to explore detection efficiency in complex samples. Raw cow milk was spiked with melamine at a concentration of $0.5 \mathrm{ng} \mu \mathrm{L}^{-1}$. Human breast milk samples on 42 days postpartum were collected from 20 volunteers. The samples were kept in sterile tubes and stored at $-80^{\circ} \mathrm{C}$ until use. Before sample collection, a written informed consent was given to each volunteer. The investigation protocol in this study was approved by the Ethical Committee of Xinhua Hospital (XHEC-C2014016) and School of Biomedical Engineering, Shanghai Jiao Tong University.

\subsection{MALDI MS Analysis}

Silver nanoshells were dispersed in deionized water at a concentration of $0.5 \mathrm{mg} \mathrm{mL}^{-1}$ for matrix use. In a typical MALDI MS experiment, $0.5 \mu \mathrm{L}$ of analyte solution was 
spotted on the stainless steel target plate and dried in air at room temperature, followed by adding $0.5 \mu \mathrm{L}$ of matrix slurry which was dried before MALDI MS analysis. Mass spectra were recorded on a 5800 Proteomics Analyzer (Applied Biosystems, Framingham, MA, USA) equipped with the Nd:YAG laser (1 kHz $355 \mathrm{~nm})$. Spectra acquisitions were carried out in the positive reflector ion mode, employing delayed extraction with a repetition rate of $200 \mathrm{~Hz}$ and an acceleration voltage of $20 \mathrm{kV}$. The delay time for this experiment was optimized to $200 \mathrm{~ns}$. The number of laser shots was 200 per analysis for all LDI MS experiments. The $\mathrm{m} / \mathrm{z}$ range was chosen according to the mass of the sample. The tandem mass spectra (MS/MS) of selected peaks of lactose and melamine from bio-samples were collected and compared with standards for identification purpose. MS/MS were performed with the precursor mass \pm 0.50 Da. All spectra were directly used without any smoothing procedures [15].

\subsection{Molecules Quantification}

For isotopic quantification, standard lactose was dissolved in deionized water by step-wise dilutions to obtain the concentrations ranging from 50 to $800 \mathrm{ng} \mu \mathrm{L}^{-1}$. The lactose isotope was dissolved in deionized water at a concentration of $100 \mathrm{ng} \mu \mathrm{L}^{-1}$. Then, the standard lactose solutions were mixed with lactose isotope solution at a volume ratio of $1: 1$ to obtain the calibration curve. Typically, lactose quantitation was performed by considering the area under the peaks of sodium or potassium adducts of the analyte and internal standard. The relative peak area ratio of the analytes/isotopes (A/I) from five independent experiments was recorded with data shown as the mean $\pm \mathrm{SD}(n=5)$ for intra-batch analysis. Five replicates were detected for batch-to-batch analysis. To further validate the isotopic quantification method, intraday results were collected by analyzing the $40-$ and $80-\mu \mathrm{g} \mu \mathrm{L}^{-1}$ standard lactose solutions. Interday results were collected by analyzing the same samples over five consecutive days to calculate the coefficient of variation $(\mathrm{CV})$.

For biochemical quantitation, the commercial lactose and D-galactose assay kit was purchased from Megazyme International, Ireland. In brief, the enzymatic method required sample purification using the Carrez method [36, 37]. Breast milk $(100 \mu \mathrm{L})$ was added into a $10-\mathrm{mL}$ volumetric flask with $6 \mathrm{~mL}$ of deionized water and mixed at $50{ }^{\circ} \mathrm{C}$ for $15 \mathrm{~min}$. Then, $200 \mu \mathrm{L}$ of Carrez I solution (85 $\mathrm{mM}$ potassium hexacyanoferrate) was added, followed by $2 \mathrm{~mL}$ of Carrez II solution ( $250 \mathrm{mM}$ zinc sulfate). Next, $400 \mu \mathrm{L}$ of $100 \mathrm{mM} \mathrm{NaOH}$ was added and the mixture was diluted to a volume of $10 \mathrm{~mL}$ with deionized water. Finally, after filtration through Whatman No. 1 filter paper, the detection assay was performed using the AuCy UV1900 spectrophotometer.

\section{Results and Discussion}

\subsection{Preparation and Characterization of Materials}

Silver nanoshells were synthesized by silver mirror reactions, through the multi-cycled coating of silver nanoparticles on the surface of silica spheres. We used monodispersed silica spheres (by the Stöber method) with an average size of $167.1 \pm 1.3 \mathrm{~nm}$ and polydispersity index (PDI) of $0.024 \pm 0.010$ (Fig. S1 and Table S1), according to dynamic light scattering (DLS) analysis. Three cycles of silver mirror reactions were conducted for material optimization, and the resulting $\mathrm{SiO}_{2} @ \mathrm{Ag}$ had an increased size of $\sim 180 \mathrm{~nm}$ (Fig. 1b), owing to the introduction of the silver layer. In addition, silver nanoshells were negatively charged with a zeta potential of $-21.0 \pm 0.8 \mathrm{mV}$ (Table S1), which was ideal for the production of $\mathrm{Na}^{+} / \mathrm{K}^{+}$/ $\mathrm{Ag}^{+}$adducts during LDI. We also prepared bare silver nanoparticles with different sizes of $14.5 \pm 1.3$, $34.3 \pm 2.5$, and $94.3 \pm 7.7 \mathrm{~nm}$ for control experiments (Fig. S2 and Table S1). Notably, the silver nanoshells displayed distinct optical properties from the silica spheres (Fig. 1c), with an absorption peak at $\sim 433 \mathrm{~nm}$ by ultraviolet-visible (UV-Vis) spectroscopy owing to the Mie plasmon resonance excitation from silver nanoparticles [38]. Therefore, we demonstrated that the silica-silver coreshell particles with absorption band close to $355 \mathrm{~nm}$ (the wavelength for Nd:YAG laser used for LDI subsequently) was ideal for matrix use in MS.

The structure of silver nanoshells was further investigated by electron microscopy methods. As shown in the SEM image (Fig. 1d), the silica spheres were loaded with silver nanoparticles layer $(\sim 10 \mathrm{~nm})$ to form specific nano-gaps on surface, agreed to TEM image (Fig. 1e) and STEM (for elemental mapping) images (Figs. 1f and S3ac). A clear SAED pattern was observed, confirming polycrystalline silver with [111], [200], [220], and [311] rings as indexed (Fig. 1g) [39]. In addition, HRTEM displayed the typical inter planar spacing of $2.04 \AA$ for silver composites along the [200] direction (inset of Fig. 1g) [39-41]. In order to check the composition of the materials, we recorded the corresponding EDX spectra to demonstrate the presence of silver (Fig. S3d) and further quantitated the silver loading ratio of $14.87 \mathrm{wt} \%$ through elemental analysis. The above results were consistent with previous DLS and UV-Vis analyses, validating the structures of silver nanoshells. Nano-gaps of silver nanoshells afforded nanoscale roughness and crevices, for selective trapping of 
small molecules (MW $\sim<500 \mathrm{Da}$ ) for energy transfer, rather than large molecules [15, 32, 33].

\subsection{Detection and Identification of Small Nutrients}

The silver nanoshells were used for direct LDI MS detection of small nutrients, using lactose as the standard. Considering the existence of salts and proteins in real-case samples, we studied the salt tolerance and protein endurance of silver nanoshells. We obtained sodium adducted signal at an $\mathrm{m} / \mathrm{z}$ of $365.11[\mathrm{M}+\mathrm{Na}]^{+}$and the silver adducted signal at an $\mathrm{m} / \mathrm{z}$ of $449.03\left[\mathrm{M}+{ }^{107} \mathrm{Ag}\right]^{+}$and $451.03\left[\mathrm{M}+{ }^{109} \mathrm{Ag}\right]^{+}$in the mass spectrum (Fig. 2a), dealing with a bio-mixture containing proteins (BSA, $\left.5 \mathrm{mg} \mathrm{mL}^{-1}\right)$ and salts $(\mathrm{NaCl}, 0.5 \mathrm{M})$ with trace lactose. We also demonstrated the better performance of silver nanoshells in LDI MS analysis of small molecules (lactose and melamine), over bare silver nanoparticles with different sizes and silica spheres (Fig. S4). Further, trace breast milk sample (down to $6.25 \mathrm{~nL}$, Fig. S5) was detected. We observed a series of molecular peaks in the low mass range $(\sim<500 \mathrm{Da}$, Fig. 2b), without any apparent signals in high mass range (Fig. S6). Competitive silver ions may cationize molecules containing polar functional groups (e.g., $-\mathrm{OH})$ via an ion-dipole interaction $[42,43]$ and $\pi$ bonds as per the Dewar model $[44,45]$. Due to the selective LDI process being similar to previous reports, we concluded that the silver nanoshells enabled detection of small nutrients (e.g., lactose) in trace complex bio-mixtures without any separation or enrichment.
An MS/MS analysis of the molecular peaks of lactose was performed for identification purpose. The molecular peaks were fragmented at an $\mathrm{m} / \mathrm{z}$ of 365.11 for $[\mathrm{M}+\mathrm{Na}]^{+}$ (standards and milk samples in Fig. 2c, d), providing fragments ions at an $\mathrm{m} / z$ of 185.04 for $\left[\mathrm{C}_{6} \mathrm{H}_{10} \mathrm{O}_{5}+\mathrm{Na}\right]^{+}$, 203.05 for $\left[\mathrm{C}_{6} \mathrm{H}_{12} \mathrm{O}_{6}+\mathrm{Na}\right]^{+}, 305.08$ for $\left[\mathrm{C}_{10} \mathrm{H}_{18} \mathrm{O}_{9}\right.$ $+\mathrm{Na}]^{+}$, and 347.09 for $\left[\mathrm{C}_{12} \mathrm{H}_{20} \mathrm{O}_{10}+\mathrm{Na}\right]^{+}$. Similarly, we fragmented the molecular peaks at an $\mathrm{m} / \mathrm{z}$ of 449.03 $\left[\mathrm{M}+{ }^{107} \mathrm{Ag}\right]^{+}$(standards and milk samples in Fig. 2e, f), providing fragments ions at an $\mathrm{m} / \mathrm{z}$ of 133.05 for $\left[\mathrm{C}_{5} \mathrm{H}_{9} \mathrm{O}_{4}\right]^{+}, 178.92$ for $\left[\mathrm{C}_{3} \mathrm{H}_{4} \mathrm{O}_{2}+{ }^{107} \mathrm{Ag}\right]^{+}, 286.97$ for $\left[\mathrm{C}_{6} \mathrm{H}_{12} \mathrm{O}_{6}+{ }^{107} \mathrm{Ag}\right]^{+}$, and 388.99 for $\left[\mathrm{C}_{10} \mathrm{H}_{18} \mathrm{O}_{9}+{ }^{107}\right.$ $\mathrm{Ag}]^{+}$. By comparing these MS/MS results, we identified the lactose in breast milk in situ. Besides the accuracy of MS $(\sim \mathrm{ppm})$, the presence of multi-signals for $\mathrm{Na}^{+} / \mathrm{K}^{+} /$ $\mathrm{Ag}^{+}$adduction increased the confidence levels of identification. Moreover, MS/MS analysis confirmed the structure of the small molecules and displayed strong application potential when coupled with silver nanoshells.

\subsection{Isotopic Quantification in Milk Samples}

LDI MS is normally qualitative or semiquantitative, due to the non-predictable ionization process [17, 46, 47]. For quantification, we spiked isotopes as the internal standards (IS), which afforded molecular peaks at an $\mathrm{m} / \mathrm{z}$ of 371.11 $[\mathrm{M}+\mathrm{Na}]^{+}$for the isotopes using the silver nanoshells (Fig. 3a, one representative mass spectrum of an analyte from five experiments; the other four spectra can be found in Fig. S7). The calibration curves for the sodium (Fig. 3b) and silver adducts (Fig. S8) were recorded with the
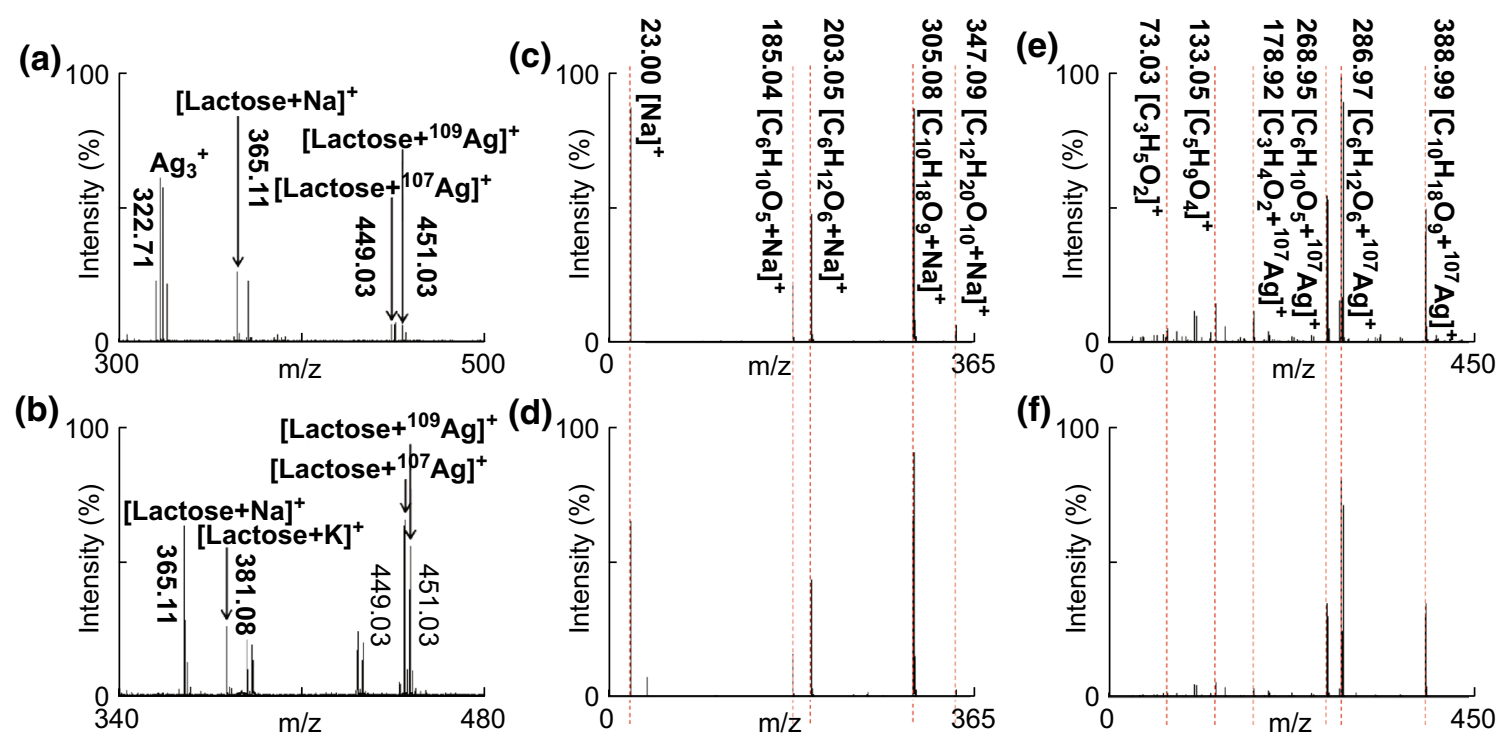

Fig. 2 MALDI MS analysis. a Mass spectrum of $50 \mathrm{ng} \mu \mathrm{L}^{-1}$ lactose in a $5-\mathrm{mg} \mathrm{mL}^{-1}$ bovine serum albumin solution containing $0.5 \mathrm{M} \mathrm{NaCl}$. b Mass spectrum of $6.25 \mathrm{~nL}$ of breast milk sample with 80 -fold dilution. Tandem mass spectra of sodium adducted lactose at an $m / z$ of 365.11 for $[\mathrm{M}+\mathrm{Na}]^{+}$in $\mathbf{c}$ standard sample and $\mathbf{d}$ breast milk. Tandem mass spectra of silver adducted lactose at an $\mathrm{m} / \mathrm{z}$ of $449.03 \mathrm{for}\left[\mathrm{M}+{ }^{107} \mathrm{Ag}\right]^{+}$in e standard sample and $\mathbf{f}$ breast milk 

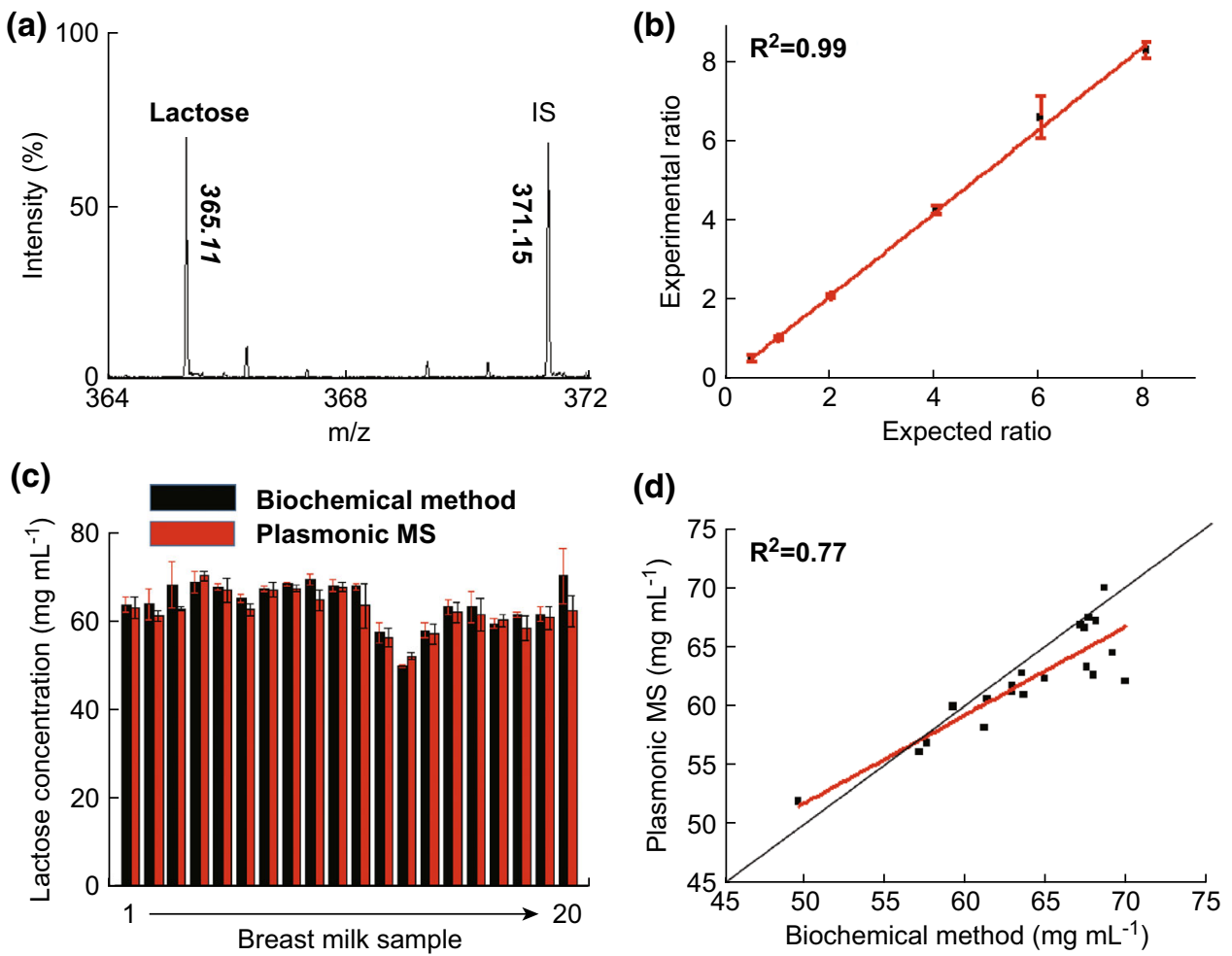

Fig. 3 Quantitation of small nutrients. a Representative mass spectrum of lactose with its isotope as the internal standard (IS). b The calibration curve obtained by plotting the experimental ratio of analyte/isotope (A/I) for sodium adducts as a function of the expected ratio of A/I for lactose. c Comparison of results obtained by the plasmonic MS and biochemical method for 20 breast milk samples. d Linear correlation of the quantification results from the plasmonic MS and biochemical method

analyte/IS ratios ranging from 0.5 to 8 . Potassium adducts were not used due to low peak intensities. We calculated the coefficient of determination $\left(R^{2}\right)$ of 0.99 for both the sodium and silver adducts, demonstrating isotopic quantification successfully coupled with the silver nanoshellsassisted LDI MS. We validated the quantification method for lactose by intraday, interday, intra-batch, and batch-tobatch analysis as summarized in Table S2.

The lactose levels in 20 breast milk samples were quantitated by the plasmonic MS and compared to the conventional biochemical method (Fig. 3c, Table S3). The isotopic quantification afforded an average recovery of $105.3 \%$ and a coefficient of variation $(\mathrm{CV})$ of $6.2 \%$, which was comparable to the enzymatic kit that afforded an average recovery of $105.0 \%$ and a CV of $3.6 \%$ (Fig. S9). These two approaches showed reasonable consistency as per the linear fit method, with an $R^{2}$ of 0.77 (Fig. 3d). The biochemical method is the current gold standard in use, relying on the reaction between analytes and enzymes for colorimetric detection to quantitate small molecules [48]. More specifically, the biochemical method is indirect in nature, detecting galactose based on the hydrolysis of lactose into galactose and glucose by $\beta$-galactosidase. In contrast, the plasmonic MS method directly detects lactose. Notably, plasmonic MS can be advantageous in terms of speed (reaction free, in minute overall analysis) and sensitivity ( $\sim 6 \mathrm{~nL}$ of sample required), compared to the biochemical method that requires several hours for analysis (including bio-reactions and pre-treatment steps) and utilizes milliliters of sample.

\subsection{Sensitive Detection of Small Toxins}

Besides the nutrient molecules, our approach achieved the detection of small toxins as well. For example, we detected standard melamine solutions prepared in gradient concentrations, affording molecular peaks at an $\mathrm{m} / \mathrm{z}$ of 232.96 $\left[\mathrm{M}+{ }^{107} \mathrm{Ag}\right]^{+}$and $234.96\left[\mathrm{M}+{ }^{109} \mathrm{Ag}\right]^{+}$(Fig. 4a). The experimentally determined LOD of melamine was below $0.1 \mathrm{ng} \mu \mathrm{L}^{-1}(S / N>3)$ and was comparable to the best results of previously reported methods [49-51]. A melamine-spiked milk sample was directly detected without any separation or enrichment (Fig. 4b), similar to the detection of lactose, showing an $\mathrm{m} / \mathrm{z}$ of 232.96 for $\left[\mathrm{M}+{ }^{107} \mathrm{Ag}\right]^{+}$and 234.96 for $\left[\mathrm{M}+{ }^{109} \mathrm{Ag}\right]^{+}$(Fig. 4c). We conducted MS/MS analysis of the molecular peaks of melamine for identification purpose (Fig. 4d). We fragmented the molecular peak at an $\mathrm{m} / \mathrm{z}$ of $232.96\left[\mathrm{M}+{ }^{107} \mathrm{Ag}\right]^{+}$, providing fragments ions at an $\mathrm{m} / \mathrm{z}$ of 43.03 for $\left[\mathrm{CH}_{3} \mathrm{~N}_{2}\right]^{+}, 68.02$ for 
(a)

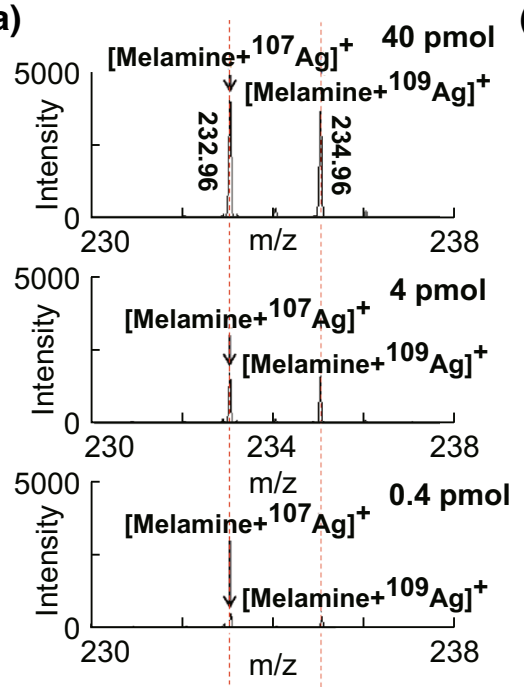

(b)

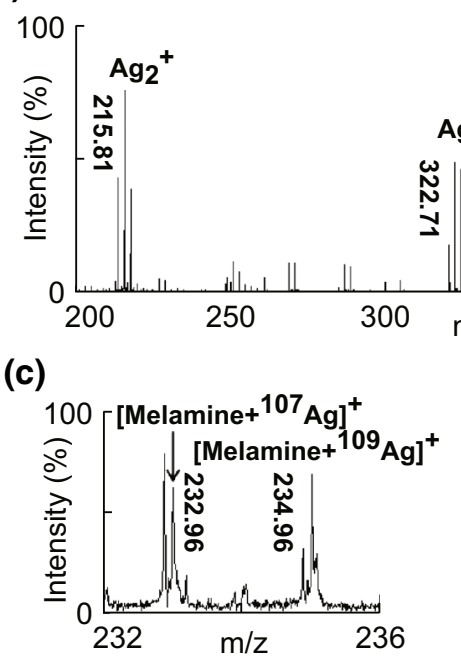

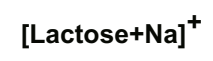

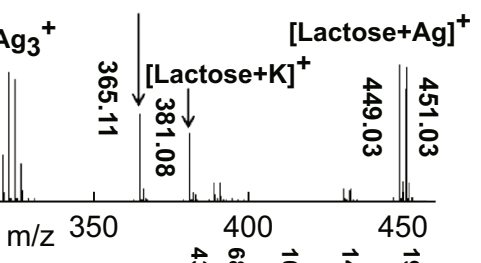

(d)

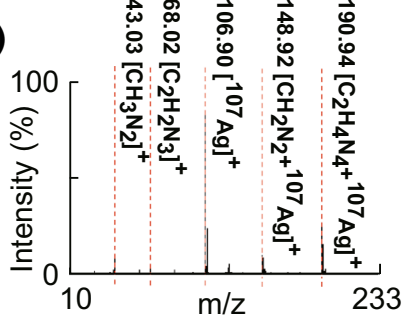

Fig. 4 Detection of toxins. a Plasmonic MS analysis of melamine prepared in a concentration gradient. Plasmonic MS analysis of raw milk samples spiked with melamine at a concentration of $0.5 \mathrm{ng} \mu \mathrm{L}^{-1}$, showing $\mathbf{b}$ an $\mathrm{m} / \mathrm{z}$, range from 200 to 450 , $\mathbf{c}$ an $m / z$ range from 232 to 236 , and d the tandem mass spectrum of melamine at an $\mathrm{m} / \mathrm{z}$ of 232.96 for $\left[\mathrm{M}+{ }^{107} \mathrm{Ag}\right]^{+}$

$\left[\mathrm{C}_{2} \mathrm{H}_{2} \mathrm{~N}_{3}\right]^{+}, 148.92$ for $\left[\mathrm{CH}_{2} \mathrm{~N}_{2}+{ }^{107} \mathrm{Ag}\right]^{+}$, and 190.94 for $\left[\mathrm{C}_{2} \mathrm{H}_{4} \mathrm{~N}_{4}+{ }^{107} \mathrm{Ag}\right]^{+}$.

Heavy demand in the food industry has led to unethical food adulteration practices with financial gains for unscrupulous producers. This adulteration resulted in the hospitalization of approximately 300,000 children in 2008 [6]. Considering the needs to track small toxins in food samples, many MS methods were developed for analysis of melamine, such as gas chromatography (GC) [52], liquid chromatography (LC) [53], and desorption electrosprayionization (DESI) [54]. Despite reasonable progress, current MS methods normally require tedious sample pretreatment procedures and long experimental time ( $\sim$ hours). Our approach tackled the above challenges and can be employed in the food industry for large-scale application.

\section{Conclusion}

In summary, we herein reported a plasmonic MALDI MS approach to identify and quantitate small molecules in realcase emulsion analysis. Due to the sensitive LDI process employing plasmonic silver nanoparticles as matrices, our approach afforded trace sample consumption down to $\mathrm{nL}$, fast analytical process in minutes, and minimum pretreatment without enrichment/separation. This work contributes to the near-future application of MALDI MS in a broad field and personalized design of plasmonic materials for real-case bio-analysis.
Acknowledgements We thank the financial support from Project 81771983, 81750110544, 81750410695, 81650110523, and 81471096 (to LXQ) by National Natural Science Foundation of China (NSFC), Project 16441909300 by Shanghai Science and Technology Commission, Project 2017YFC0909000 by Ministry of Science and Technology of China. This work is also sponsored by the Program for Professor of Special Appointment (Eastern Scholar) at Shanghai Institutions of Higher Learning (TP2015015) and supported by 14DZ2272400 Shanghai Key Laboratory of Pediatric Gastroenterology and Nutrition (to WC). KQ is grateful for the NML Researcher Award 2016.

Open Access This article is distributed under the terms of the Creative Commons Attribution 4.0 International License (http://crea tivecommons.org/licenses/by/4.0/), which permits unrestricted use, distribution, and reproduction in any medium, provided you give appropriate credit to the original author(s) and the source, provide a link to the Creative Commons license, and indicate if changes were made.

\section{References}

1. M. Gallo, P. Ferranti, The evolution of analytical chemistry methods in foodomics. J. Chromatogr. A 1428, 3-15 (2016). https://doi.org/10.1016/j.chroma.2015.09.007

2. R.J. McGorrin, One hundred years of progress in food analysis. J. Agric. Food Chem. 57(18), 8076-8088 (2009). https://doi.org/ $10.1021 / \mathrm{jf} 900189 \mathrm{~s}$

3. J.H. Cummings, A.M. Stephen, Carbohydrate terminology and classification. Eur. J. Clin. Nutr. 61, S5-S18 (2007). https://doi. org/10.1038/sj.ejcn.1602936

4. W.J. Craig, A.R. Mangels, Ada, Position of the American dietetic association: vegetarian diets. J. Am. Diet. Assoc. 109(7), 1266-1282 (2009). https://doi.org/10.1016/j.jada.2009.05.027

5. J.E. Arsenault, K.H. Brown, Effects of protein or amino-acid supplementation on the physical growth of young children in lowincome countries. Nutr. Rev. 75(9), 699-717 (2017). https://doi. org/10.1093/nutrit/nux027 
6. J.R. Ingelfinger, Melamine and the global implications of food contamination. N. Engl. J. Med. 359(26), 2745-2748 (2008). https://doi.org/10.1056/NEJMp0808410

7. H.M. Lam, J. Remais, M.C. Fung, L. Xu, S.S.M. Sun, Food supply and food safety issues in China. Lancet 381(9882), 2044-2053 (2013). https://doi.org/10.1016/S0140-6736(13)60776-X

8. X. Sun, J.J. Wan, K. Qian, Designed microdevices for in vitro diagnostics. Small Methods 1(10), 1700196 (2017). https://doi. org/10.1002/smtd.201700196

9. H.V. Botitsi, S.D. Garbis, A. Economou, D.F. Tsipi, Current mass spectrometry strategies for the analysis of pesticides and their metabolites in food and water materices. Mass Spectrom. Rev. 30(5), 907-939 (2011). https://doi.org/10.1002/mas.20307

10. M. Herrero, C. Simo, V. Garcia-Canas, E. Ibanez, A. Cifuentes, Foodomics: MS-based strategies in modern food science and nutrition. Mass Spectrom. Rev. 31(1), 49-69 (2012). https://doi. org/10.1002/mas.20335

11. V. Kasicka, Recent developments in capillary and microchip electroseparations of peptides (2013-middle 2015). Electrophoresis 37(1), 162-188 (2016). https://doi.org/10.1002/elps. 201500329

12. C. Rejeeth, X. Pang, R. Zhang, W. Xu, X. Sun et al., Extraction, detection, and profiling of serum biomarkers using designed $\mathrm{Fe}_{3} \mathrm{O}_{4} @ \mathrm{SiO}_{2} @ \mathrm{HA}$ core-shell particles. Nano Res. 11(1), 68-79 (2018). https://doi.org/10.1007/s12274-017-1591-6

13. B. Liu, Y. Li, H. Wan, L. Wang, W. Xu et al., High performance, multiplexed lung cancer biomarker detection on a plasmonic gold chip. Adv. Funct. Mater. 26(44), 7994-8002 (2016). https://doi. org/10.1002/adfm.201603547

14. R. Zenobi, Single-cell metabolomics: analytical and biological perspectives. Science 342(6163), 1243259 (2013). https://doi.org/ $10.1126 /$ science. 1243259

15. L. Huang, J. Wan, X. Wei, Y. Liu, J. Huang et al., Plasmonic silver nanoshells for drug and metabolite detection. Nat. Commun. 8, 220 (2017). https://doi.org/10.1038/s41467-017-00220-4

16. Y. Li, L. Yan, Y. Liu, K. Qian, B. Liu, P. Yang, B. Liu, Highefficiency nano/micro-reactors for protein analysis. RSC Adv. 5(2), 1331-1342 (2015). https://doi.org/10.1039/c4ra12333f

17. M. Karas, D. Bachmann, U. Bahr, F. Hillenkamp, Matrix-assisted ultraviolet laser desorption of non-volatile compounds. Int. J. Mass Spectrom. Ion Process. 78, 53-68 (1987). https://doi.org/ 10.1016/0168-1176(87)87041-6

18. K. Wu, J. Chen, J.R. McBride, T. Lian, Efficient hot-electron transfer by a plasmon-induced interfacial charge-transfer transition. Science 349(6248), 632-635 (2015). https://doi.org/10. 1126/science.aac5443

19. M.L. Brongersma, N.J. Halas, P. Nordlander, Plasmon-induced hot carrier science and technology. Nat. Nanotechnol. 10(1), 25-34 (2015). https://doi.org/10.1038/nnano.2014.311

20. C. Lei, K. Qian, O. Noonan, A. Nouwensa, C. Yu, Applications of nanomaterials in mass spectrometry analysis. Nanoscale 5(24), 12033-12042 (2013). https://doi.org/10.1039/c3nr04194h

21. I. Ocsoy, B. Gulbakan, M.I. Shukoor, X. Xiong, T. Chen, D.H. Powell, W. Tan, Aptamer-conjugated multifunctional nanoflowers as a platform for targeting, capture, and detection in laser desorption ionization mass spectrometry. ACS Nano 7(1), 417-427 (2013). https://doi.org/10.1021/nn304458m

22. Y.C. Liu, C.K. Chiang, H.T. Chang, Y.F. Lee, C.C. Huang, Using a functional nanogold membrane coupled with laser desorption/ ionization mass spectrometry to detect lead ions in biofluids. Adv. Funct. Mater. 21(23), 4448-4455 (2011). https://doi.org/10.1002/ adfm. 201101248

23. K. Qian, L. Zhou, J. Liu, J. Yang, H. Xu et al., Laser engineered graphene paper for mass spectrometry imaging. Sci. Rep. 3, 1415 (2013). https://doi.org/10.1038/srep01415
24. T. Liu, L. Qu, K. Qian, J. Liu, Q. Zhang, L. Liu, S. Liu, Raspberry-like hollow carbon nanospheres with enhanced matrix-free peptide detection profiles. Chem. Commun. 52(8), 1709-1712 (2016). https://doi.org/10.1039/c5cc07912h

25. G. Lim, Z. Chen, J. Clark, R.G.S. Goh, W. Ng, H. Tan, R.H. Friend, P.K.H. Ho, L. Chua, Giant broadband nonlinear optical absorption response in dispersed graphene single sheets. Nat. Photonics 5(9), 554-560 (2011). https://doi.org/10.1038/nphoton. 2011.177

26. Y. Hu, K. Qian, P. Yuan, Y. Wang, C. Yu, Synthesis of largepore periodic mesoporous organosilica. Mater. Lett. 65(1), 21-23 (2011). https://doi.org/10.1016/j.matlet.2010.08.078

27. S.A. Stopka, C. Rong, A.R. Korte, S. Yadavilli, J. Nazarian, T.T. Razunguzwa, N.J. Morris, A. Vertes, Molecular imaging of biological samples on nanophotonic laser desorption ionization platforms. Angew. Chem. Int. Ed. 55(14), 4482-4486 (2016). https://doi.org/10.1002/anie.201511691

28. K.P. Law, J.R. Larkin, Recent advances in SALDI-MS techniques and their chemical and bioanalytical applications. Anal. Bioanal. Chem. 399(8), 2597-2622 (2011). https://doi.org/10. 1007/s00216-010-4063-3

29. X. Wei, Z. Liu, X. Jin, L. Huang, D.D. Gurav, X. Sun, B. Liu, J. Ye, K. Qian, Plasmonic nanoshells enhanced laser desorption/ ionization mass spectrometry for detection of serum metabolites. Anal. Chim. Acta 950, 147-155 (2017). https://doi.org/10.1016/j. aca.2016.11.017

30. J. Gan, X. Wei, Y. Li, J. Wu, K. Qian, B. Liu, Designer $\mathrm{SiO}_{2} @ \mathrm{Au}$ nanoshells towards sensitive and selective detection of small molecules in laser desorption ionization mass spectrometry. Nanomedicine 11(7), 1715-1723 (2015). https://doi.org/10.1016/ j.nano.2015.06.010

31. C.K. Chiang, W.T. Chen, H.T. Chang, Nanoparticle-based mass spectrometry for the analysis of biomolecules. Chem. Soc. Rev. 40(3), 1269-1281 (2011). https://doi.org/10.1039/c0cs00050g

32. J. Wu, X. Wei, J.R. Gan, L. Huang, T. Shen, J.T. Lou, B.H. Liu, J.X.J. Zhang, K. Qian, Multifunctional magnetic particles for combined circulating tumor cells isolation and cellular metabolism detection. Adv. Funct. Mater. 26(22), 4016-4025 (2016). https://doi.org/10.1002/adfm.201504184

33. X. Sun, L. Huang, R. Zhang, W. Xu, J. Huang et al., Metabolic fingerprinting on a plasmonic gold chip for mass spectrometry based in vitro diagnostics. ACS Cent. Sci. 4(2), 223-229 (2018). https://doi.org/10.1021/acscentsci.7b00546

34. W. Stöber, A. Fink, E. Bohn, Controlled growth of monodisperse silica spheres in the micron size range. J. Colloid Interface Sci. 26(1), 62-69 (1968). https://doi.org/10.1016/0021-9797(68)90272-5

35. P.C. Lee, D. Meisel, Adsorption and surface-enhanced Raman of dyes on silver and gold sols. J. Phys. Chem. 86(17), 3391-3395 (1982). https://doi.org/10.1021/j100214a025

36. K. Fujioka, T. Shibamoto, Quantitation of volatiles and nonvolatile acids in an extract from coffee beverages: correlation with antioxidant activity. J. Agric. Food Chem. 54(16), 6054-6058 (2006). https://doi.org/10.1021/jf060460x

37. F. Rincon, B. Martinez, J.M. Delgado, Detection of factors influencing nitrite determination in meat. Meat Sci. 65(4), 1421-1427 (2003). https://doi.org/10.1016/s0309-1740(03)00065-2

38. Z. Deng, M. Chen, L. Wu, Novel method to fabricate $\mathrm{SiO}_{2} / \mathrm{Ag}$ composite spheres and their catalytic, surface-enhanced Raman scattering properties. J. Phys. Chem. C 111(31), 11692-11698 (2007). https://doi.org/10.1021/jp073632h

39. Y. Cai, X. Piao, W. Gao, Z. Zhang, E. Nie, Z. Sun, Large-scale and facile synthesis of silver nanoparticles via a microwave method for a conductive pen. RSC Adv. 7(54), 34041-34048 (2017). https://doi.org/10.1039/c7ra05125e

40. W. Zhang, Y. Liu, R. Cao, Z. Li, Y. Zhang, Y. Tang, K. Fan, Synergy between crystal strain and surface energy in 
morphological evolution of five-fold-twinned silver crystals. J. Am. Chem. Soc. 130(46), 15581-15588 (2008). https://doi.org/ 10.1021/ja805606q

41. S.H. Yu, X.J. Cui, L.L. Li, K. Li, B. Yu, M. Antonietti, H. Colfen, From starch to metal/carbon hybrid nanostructures: hydrothermal metal-catalyzed carbonization. Adv. Mater. 16(18), 1636-1640 (2004). https://doi.org/10.1002/adma.200400522

42. S.A. Mcluckey, A.E. Schoen, R.G. Cooks, Silver ion affinities of alcohols as ordered by mass spectrometry/mass spectrometry. J. Am. Chem. Soc. 104(3), 848-850 (1982). https://doi.org/10. 1021/ja00367a035

43. D. Zakett, A.E. Schoen, R.G. Cooks, P.H. Hemberger, Laserdesorption mass spectrometry/mass spectrometry and the mechanism of desorption ionization. J. Am. Chem. Soc. 12(25), 1295-1297 (1981). https://doi.org/10.1021/ja00395a086

44. L.I. Grace, A. Abo-Riziq, M.S. de Vries, An in situ silver cationization method for hydrocarbon mass spectrometry. J. Am. Soc. Mass Spectrom. 16(4), 437-440 (2005). https://doi.org/10. 1016/j.jasms.2004.12.011

45. A.U. Jackson, T. Shum, E. Sokol, A. Dill, R.G. Cooks, Enhanced detection of olefins using ambient ionization mass spectrometry: $\mathrm{Ag}^{+}$adducts of biologically relevant alkenes. Anal. Bioanal. Chem. 399(1), 367-376 (2011). https://doi.org/10.1007/s00216010-4349-5

46. K. Qian, W. Gu, P. Yuan, F. Liu, Y. Wang, M. Monteiro, C. Yu, Enrichment and detection of peptides from biological systems using designed periodic mesoporous organosilica microspheres. Small 8(2), 231-236 (2012). https://doi.org/10.1002/smll. 201101770

47. K. Qian, F. Liu, J. Yang, X. Huang, W. Gu, S. Jambhrunkar, P. Yuan, C. Yu, Pore size-optimized periodic mesoporous organosilicas for the enrichment of peptides and polymers. RSC Adv. 3(34), 14466-14472 (2013). https://doi.org/10.1039/ c3ra41332b

48. A. Trani, G. Gambacorta, P. Loizzo, A. Cassone, C. Fasciano, A.V. Zambrini, M. Faccia, Comparison of HPLC-RI, LC/MS-MS and enzymatic assays for the analysis of residual lactose in lactose-free milk. Food Chem. 233, 385-390 (2017). https://doi.org/ 10.1016/j.foodchem.2017.04.134

49. L. Li, B.X. Li, Sensitive and selective detection of cysteine using gold nanoparticles as colorimetric probes. Analyst 134(7), 1361-1365 (2009). https://doi.org/10.1039/b819842j

50. X. Liang, H. Wei, Z. Cui, J. Deng, Z. Zhang, X. You, X.E. Zhang, Colorimetric detection of melamine in complex matrices based on cysteamine-modified gold nanoparticles. Analyst 136(1), 179-183 (2011). https://doi.org/10.1039/c0an00432d

51. S. Zhang, Z. Yu, N. Hu, Y. Sun, Y. Suo, J. You, Sensitive determination of melamine leached from tableware by reversed phase high-performance liquid chromatography using 10-methylacridone-2-sulfonyl chloride as a pre-column fluorescent labeling reagent. Food Control 39, 25-29 (2014). https://doi.org/10.1016/j. foodcont.2013.10.037

52. H. Miao, S. Fan, Y.N. Wu, L. Zhang, P.P. Zhou, J.G. Li, H.J. Chen, Y.F. Zhao, Simultaneous determination of melamine, ammelide, ammeline, and cyanuric acid in milk and milk products by gas chromatography-tandem mass spectrometry. Biomed. Environ. Sci. 22(2), 87-94 (2009). https://doi.org/10.1016/S08953988(09)60027-1

53. A. Desmarchelier, M.G. Cuadra, T. Delatour, P. Mottier, Simultaneous quantitative determination of melamine and cyanuric acid in cow's milk and milk-based infant formula by liquid chromatography-electrospray ionization tandem mass spectrometry. J. Agric. Food Chem. 57(16), 7186-7193 (2009). https://doi. org/10.1021/jf901355v

54. S. Yang, J. Ding, J. Zheng, B. Hu, J. Li, H. Chen, Z. Zhou, X. Qiao, Detection of melamine in milk products by surface desorption atmospheric pressure chemical ionization mass spectrometry. Anal. Chem. 81(7), 2426-2436 (2009). https://doi.org/ 10.1021/ac900063u 